\title{
Extending Maternity Leave and Early Childhood Health in Zimbabwe
}

Author: Kien Le

Email: kien.le@ou.edu.vn

Affiliation: Faculty of Economics and Public Management, Ho Chi Minh City Open

University

\begin{abstract}
This paper explores the relationship between extending maternity leave and child health. To quantify the relationship of interest, we exploit the expansion of maternity leave in Zimbabwe Labour Amendment Act of 2005 that went into effect in December 2005. We find statistical evidence on the positive association between extending maternity leave and child health. Quantitatively, those exposed to the maternity leave extension grow 0.522 standard deviations taller for their age, weigh 0.959 standard deviations more for their age, and weigh 0.580 standard deviations more for their height. The findings emphasize the significance of increasing maternity leave in enhancing child health.
\end{abstract}

Keywords: Maternity Leave, Child Health, Zimbabwe 


\section{Introduction}

In 2018, stunted children (those being too short) and wasted children (those being too thin) accounted for $22 \%$ and $7 \%$ of all children across the globe, respectively (UNICEF, 2019). According to these statistics, poor early-life health is widespread in many nations. Moreover, it has been shown that poor early-life health can leave long-term consequences, such as poorer educational achievement, cognitive impairment, and lower productivity and earnings (Martorell, 1999; Le and Nguyen, 2020a). Because of such private and social costs, enhancing child health has garnered a lot of attention, with health-related legislation considered as one of the main solutions.

Several nations have expanded maternity leave regulations in order to enhance the health outcomes of the public. For example, under the Labour Amendment Act of 2005 (commencement on December 30, 2005), Zimbabwe extended the length of maternity leave from 90 to 98 days. Though it is not as lengthy as in developed nations, it is nevertheless a major improvement compared to the previous duration. Such decisions were taken based on the idea that longer maternity leaves would improve infant health and development. Prior research has shown that children whose mothers have longer leaves tend to have lower mortality rates and higher test scores (Tanaka, 2005; Baker and Milligan, 2008; Rossin, 2011). However, there is research suggesting that prolonging maternity leaves may not produce the expected benefits because of diminishing returns to leave length and unfavorable career consequences (Lyness et al., 1999; Beuchert et al., 2016).

This study brings to the debate additional evidence from Zimbabwe's maternity leave extension. To assess the impact of extending maternity leave, we conduct our analysis using five nationally representative survey waves. We find statistical evidence on the positive association between extending maternity leave and child health. Quantitatively, those exposed to the maternity leave extension grow 0.522 standard deviations taller for their age, weigh 0.959 standard deviations more for their age, and weigh 0.580 standard deviations more for their height. The findings emphasize the significance of increasing maternity leave in enhancing child health.

Previous research has reported that poor health in early childhood has detrimental impacts on adult earnings, educational achievement, and health outcomes. In addition, poor health in early childhood may have greater long-term and severe consequences in underdeveloped nations. As a result, our findings place emphasis on the importance of extending maternity leave in alleviating social and economic conditions, especially in developing countries. Furthermore, expanding maternity leave may aid in the achievement of Millennium Development Goals 4 (lower child mortality) and 5 (improve maternal health).

The study structure includes Introduction, Empirical Methodology, Results, and Conclusion. 


\section{Empirical Methodology}

The estimated regression equation in analyzing the association between extending maternity leave and child health is as follows,

$$
Y_{i j t s}=\beta_{0}+\beta_{1} M L E_{j t}+\delta_{j}+\theta_{t}+\lambda_{s}+X^{\prime}{ }_{i j t s} \Omega+\epsilon_{i j t s}
$$

where the subscripts stand for child $i$, residential cluster $j$, birth month-year $t$, and survey month-year $s$. The dependent variable $Y_{i j t s}$ depicts the health outcomes, including the anthropometric z-scores of weight-for-age, height-for-age, as well as weight-for-height. The independent variable of interest, $M L E_{j t}$ (Maternity Leave Extension), equal to one if the child was exposed to the maternity leave extension since birth, and zero otherwise. In addition, the variables $\delta_{j}, \theta_{t}$, and $\lambda_{s}$ refer to residential cluster, survey month-year, and birth month-year fixed effects. $X^{\prime}{ }_{i j t s}$ resembles a covariate of child and mother's characteristics, including: (i) child's age and squared-age in months, gender, birth order, plural birth indicator, and (ii) mother's age and squared-age, age and squared-age at birth, educational attainment, poor household indicator, and male household head indicator. The error term is represented by $\epsilon_{i j t s}$. Standard errors in the study are clustered at the residential cluster level.

We are interested in the coefficient $\beta_{1}$, which represents the quantified association between child health and extending maternity leave. The residential cluster fixed effects model is employed to quantify the effects of interest. In this model, we make comparisons in the health of children living in the same neighborhood, one of whom was exposed to the extension while the others were not. The approach utilizes the variation in exposure across children born in the same neighborhood, which can account for unobserved heterogeneity across locations. The identifying assumption is that the timing of extending maternity leave is not related to within-neighborhood unobserved factors determining child health.

\section{Data}

The data on Zimbabwean child health is taken from the Demographic and Health Survey (DHS). The Zimbabwe DHS belongs to the DHS project that gathers and disseminates nationally representative demographic and health statistics in developing countries. The primary focus of DHS is on children and their mothers, providing us information on children's health outcomes and associated attributes. These health outcomes of children include anthropometric z-scores of weight-for-age, height-for-age, as well as weight-forheight. Thus, the estimation sample in our investigation consists of survey waves reporting these health outcomes. We end up with waves 3, 4, 5, 6, and 7 of the Zimbabwe DHS covering children born between 1991 and 2015.

Our main independent variable, Maternity Leave Extension (MLE), is a zero-one dichotomous variable equal to one if maternity leave extension was implemented before the child being born, and zero otherwise. Hence, Zimbabwean children born in or after January 2006 were exposed to maternity leave extension (Maternity Leave Extension = 1).

The final estimation sample covers 17,818 Zimbabwean children. Table 1 reports summary statistics for both dependent and independent variables. Panel A shows that the average 
anthropometric z-scores for height-for-age, weight-for-age, and weight-for-height are -1.117, -0.753, and -0.055 standard deviations, respectively. According to Panel $\mathrm{B}$, the implementation of extension affected approximately $51.8 \%$ of the children. On average, mothers are 28.1 years old at the interview and 26.33 years old at childbirth. Besides, the mothers have an average of 8.125 schooling years. Around $18.1 \%$ of them are poor, and $63.7 \%$ of their households are led by a male. Furthermore, almost $49.9 \%$ of the children are male, and these children are 26.88 months old on average. The birth order is 2.909 on average. Plural births are about $1.2 \%$ of all births.

\section{Results}

Main Results - The estimated effects of extending maternity leave on child health are reported in Table 2. Each column in each panel depicts a separate regression, and the panel name signals the outcome of interest. Column 1 reports the coefficients from our most parsimonious specification, in which only the main independent variable Maternity Leave Extension is controlled for. In Column 2, we incorporate the set of fixed effects (survey month-year, birth month-year, residential cluster fixed effects) into our most parsimonious specification. In Column 3, we further take into account maternal traits, namely mother's age, squared-age, age at birth, squared-age at birth, years of schooling, being poor indicator, and male household head indicator. Column 4 presents the coefficients from our most extensive specification, in which we control for child characteristics (i.e. child's age in months, squared-age in months, gender, birth order, and being plural birth) in addition to the fixed effects and maternal traits.

Table 1: Summary Statistics

\begin{tabular}{lccc}
\hline & $\begin{array}{c}\text { Mean } \\
(1)\end{array}$ & $\begin{array}{c}\text { SD } \\
(2)\end{array}$ & $\begin{array}{c}\text { Obs. } \\
(3)\end{array}$ \\
\hline Panel A: Dependent Variables & & & \\
Height-for-age Z-score & -1.117 & 1.385 & 17,818 \\
Weight-for-age Z-score & -0.753 & 1.219 & 17,818 \\
Weight-for-height Z-score & -0.055 & 1.215 & 17,818 \\
& & & \\
Panel B: Independent Variables & & & \\
Maternity Leave Extension & 0.518 & 0.500 & 17,818 \\
Mother's Age & 28.10 & 6.680 & 17,818 \\
Mother's Age at Birth & 26.33 & 6.511 & 17,818 \\
Mother's Years of Education & 8.125 & 3.305 & 17,818 \\
Poor Household & 0.181 & 0.385 & 17,818 \\
Male Household Head & 0.637 & 0.481 & 17,818 \\
Male Child & 0.499 & 0.500 & 17,818 \\
Child's Age in Months & 26.88 & 17.03 & 17,818 \\
Child's Birth Order & 2.909 & 1.974 & 17,818 \\
Being a Plural Birth & 0.012 & 0.110 & 17,818 \\
\hline
\end{tabular}


As reported in Column 1, we find that children exposed to the extension grow 0.047 standard deviations higher for their age, weigh 0.082 standard deviations more for their age, and weigh 0.067 standard deviations more for their height. However, the coefficients based on the most parsimonious specification can only show the correlation between child health and extending maternity leave since key factors potentially affecting both extension exposure and child health are not controlled for. For example, children born later might have a better chance of enjoying both the extension and improved quality health at the same time.

In Column 2, we introduce survey month-year, birth month-year, and residential cluster fixed effects to control for possible heterogeneities in both temporal and spatial aspects such as the example mentioned above. Next, in Column 3, we account for maternal traits that could potentially bias our estimates. Highly educated mothers, for instance, are more likely to have healthier children and better access to the extension information simultaneously (Le and Nguyen, 2020b, 2021a, 2021b). Finally, Column 4 presents the coefficients derived from the most extensive regression specification, which further control for the child's attributes in addition to the fixed effects and maternal traits. We find that children exposed to the extension grow 0.522 standard deviations taller for their age, weigh 0.959 standard deviations more for their age, and weigh 0.580 standard deviations more for their height. These estimates are all statistically significant.

Table 2: Maternity Leave Extension and Child Health - Main Results

\begin{tabular}{|c|c|c|c|c|}
\hline & (1) & (2) & (3) & (4) \\
\hline \multicolumn{5}{|c|}{ Panel A: Y = Height-for-age Z-score } \\
\hline Maternity Leave Extension & $\begin{array}{c}0.047 * * \\
(0.021)\end{array}$ & $\begin{array}{c}1.459 * * * \\
(0.207)\end{array}$ & $\begin{array}{c}1.163 * * * \\
(0.205)\end{array}$ & $\begin{array}{c}0.522 * * * \\
(0.201)\end{array}$ \\
\hline Observations & 17,818 & 15,492 & 15,492 & 15,492 \\
\hline \multicolumn{5}{|c|}{ Panel B: Y = Weight-for-age Z-score } \\
\hline Maternity Leave Extension & $\begin{array}{c}0.082 * * * \\
(0.018)\end{array}$ & $\begin{array}{c}1.949 * * * \\
(0.179)\end{array}$ & $\begin{array}{c}1.628 * * * \\
(0.176)\end{array}$ & $\begin{array}{c}0.959 * * * \\
(0.171)\end{array}$ \\
\hline Observations & 17,818 & 15,492 & 15,492 & 15,492 \\
\hline \multicolumn{5}{|c|}{ Panel C: Y = Weight-for-height Z-score } \\
\hline Maternity Leave Extension & $\begin{array}{c}0.067 * * * \\
(0.018)\end{array}$ & $\begin{array}{c}1.109 * * * \\
(0.182)\end{array}$ & $\begin{array}{c}0.923 * * * \\
(0.181)\end{array}$ & $\begin{array}{c}0.580 * * * \\
(0.181)\end{array}$ \\
\hline Observations & 17,818 & 15,492 & 15,492 & 15,492 \\
\hline Child Characteristics & & & & $\mathrm{X}$ \\
\hline Mother Characteristics & & & $\mathrm{X}$ & $\mathrm{X}$ \\
\hline Fixed Effects & & $\mathrm{X}$ & $\mathrm{X}$ & $\mathrm{X}$ \\
\hline
\end{tabular}

Robustness - In this section, we employ a variety of specifications to assess the sensitivity of our findings. To begin, we incorporate the sampling weights into our regressions. According to Panel A of Table 3, we find statistical evidence that children exposed to the extension implementation are taller for their age, weigh more for their age, and weigh more 
for their height. Overall, incorporating the sampling weights had little influence on our conclusion. Furthermore, using the sampling weights may not be suitable since weighting might impair the efficiency and statistical power (Winship and Radbill, 1994; Gelman, 2007).

We next remove teenage mothers from our sample. Because teen pregnancy can endanger child health, we should be worried if the effects of maternity leave extension are driven by teen pregnancy. As a result, we limit our sample to children of mothers aged 20 and above at childbirth. According to the estimations in Panel B of Table 3, excluding teen mothers had little influence on our conclusion. We still have statistical evidence that children exposed to the extension implementation are taller for their age, weigh more for their age, and weigh more for their height.

Table 3: Maternity Leave Extension and Child Health - Robustness

\begin{tabular}{|c|c|c|c|}
\hline & $\begin{array}{l}\text { Height-for-age } \\
\text { Z-score } \\
\text { (1) }\end{array}$ & $\begin{array}{c}\text { Weight-for-height } \\
\text { Z-score } \\
(2)\end{array}$ & $\begin{array}{c}\text { Weight-for-age } \\
\text { Z-score } \\
\text { (3) }\end{array}$ \\
\hline \multicolumn{4}{|c|}{ Panel A: Weighted Regression } \\
\hline Maternity Leave Extension & $\begin{array}{c}0.365 * * \\
(0.174)\end{array}$ & $\begin{array}{c}1.028 * * * \\
(0.166)\end{array}$ & $\begin{array}{c}0.813 * * * \\
(0.176)\end{array}$ \\
\hline Observations & 15,492 & 15,492 & 15,492 \\
\hline \multicolumn{4}{|c|}{ Panel B: Excluding Teen Mothers } \\
\hline Maternity Leave Extension & $\begin{array}{c}0.665 * * * \\
(0.216)\end{array}$ & $\begin{array}{c}1.071 * * * \\
(0.185)\end{array}$ & $\begin{array}{c}0.602 * * * \\
(0.194)\end{array}$ \\
\hline Observations & 13,151 & 13,151 & 13,151 \\
\hline Child Characteristics & $\mathrm{X}$ & $\mathrm{X}$ & $\mathrm{X}$ \\
\hline Mother Characteristics & $\mathrm{X}$ & $\mathrm{X}$ & $\mathrm{X}$ \\
\hline Fixed Effects & $\mathrm{X}$ & $\mathrm{X}$ & $\mathrm{X}$ \\
\hline
\end{tabular}

Table 4: Maternity Leave Extension and Child Health - Other Measures

\begin{tabular}{|c|c|c|c|}
\hline & $\begin{array}{l}\text { Stunt } \\
\text { (1) }\end{array}$ & $\begin{array}{l}\text { Underweight } \\
\text { (2) }\end{array}$ & $\begin{array}{l}\text { Wasting } \\
\text { (3) }\end{array}$ \\
\hline Maternity Leave Extension & $\begin{array}{c}-0.147 * * \\
(0.073)\end{array}$ & $\begin{array}{c}-0.173 * * \\
(0.073)\end{array}$ & $\begin{array}{c}-0.103 * \\
(0.060)\end{array}$ \\
\hline Observations & 15,492 & 15,492 & 15,492 \\
\hline Child Characteristics & $\mathrm{X}$ & $\mathrm{X}$ & $\mathrm{X}$ \\
\hline Mother Characteristics & $\mathrm{X}$ & $\mathrm{X}$ & $\mathrm{X}$ \\
\hline Fixed Effects & $\mathrm{X}$ & $X$ & $X$ \\
\hline
\end{tabular}


We also examine whether our findings are robust to different outcome measures. The three anthropometric $\mathrm{z}$-scores are used to produce three nutrition indicators. Stunting, Underweight, and Wasting are zero-one dichotomous variables equal to one if the anthropometric z-scores for height-for-age, weight-for-age, and weight-for-height are less than -1, respectively. According to Table 4, those exposed to the extension are 14.7 percentage points less likely to be stunted, 17.3 percentage points less likely to be underweight, and 10.3 percentage points less likely to be wasted. Taken as a whole, our findings on the positive link between extending maternity leave and child health hold up to various model specifications and outcome measures.

\section{Conclusion}

We have documented compelling evidence for the beneficial impacts of maternity leave extension on early childhood health. Quantitatively, children exposed to the maternity leave extension grow 0.522 standard deviations taller for their age, weigh 0.959 standard deviations more for their age, and weigh 0.580 standard deviations more for their height. Employing alternative specifications and health measures yields the same conclusion.

Our findings on the beneficial effects of expanding maternity leave are in line with prior studies on the effects of various interventions and events on early childhood health. For instance, favorable weather conditions can reduce the likelihood of children having poor health (Deschênes et al., 2009; Le and Nguyen, 2021c, 2021d). Food scarcity or surpluses have also been reported to worsen or improve child health (Almond and Mazumder, 2011). Besides, children growing up in politically stable neighborhoods have been found to have better health (Le and Nguyen, 2020b). Various interventions on health literacy, nutrition, and cash transfers have also been reported to improve early childhood health (Ramakrishnan et al., 2014; Le and Nguyen, 2019; DeWalt and Hink, 2009; Nguyen, 2021; Fernald et al, 2008).

Previous research has reported that poor health in early childhood has detrimental impacts on adult earnings, educational achievement, and health outcomes. In addition, poor health in early childhood may have greater long-term and severe consequences in underdeveloped nations. As a result, our findings place emphasis on the importance of extending maternity leave in alleviating social and economic conditions, especially in developing countries. Furthermore, expanding maternity leave may aid in the achievement of Millennium Development Goals 4 (lower child mortality) and 5 (improve maternal health). 


\section{References}

Almond, D., \& Mazumder, B. (2011). Health capital and the prenatal environment: the effect of Ramadan observance during pregnancy. American Economic Journal: Applied Economics, 3(4), 56-85.

Baker, M., \& Milligan, K. (2008). How does job-protected maternity leave affect mothers' employment?. Journal of Labor Economics, 26(4), 655-691.

Beuchert, L. V., Humlum, M. K., \& Vejlin, R. (2016). The length of maternity leave and family health. Labour Economics, 43, 55-71.

Deschênes, O., Greenstone, M., \& Guryan, J. (2009). Climate change and birth weight. American Economic Review, 99(2), 211-17.

DeWalt, D. A., \& Hink, A. (2009). Health literacy and child health outcomes: a systematic review of the literature. Pediatrics, 124(Supplement 3), S265-S274.

Fernald, L. C., Gertler, P. J., \& Neufeld, L. M. (2008). Role of cash in conditional cash transfer programmes for child health, growth, and development: an analysis of Mexico's Oportunidades. The Lancet, 371(9615), 828-837.

Gelman, A. (2007). Struggles with survey weighting and regression modeling. Statistical Science, 22(2), 153-164.

Le, K., \& Nguyen, M. (2019). 'Bad Apple' peer effects in elementary classrooms: the case of corporal punishment in the home. Education Economics, 27(6), 557-572. 
